\title{
Inter-comparison of $\mathrm{NO}_{2}$ column densities measured by Pandora and OMI over Seoul, Korea
}

\author{
Seoyeon Yun*, Hanlim Lee**, Jhoon Kim ${ }^{\star \star}$, Ukkyo Jeong*, \\ Sang Seo Park* and Jay Herman*** \\ *Department of Atmospheric Science, Yonsei University \\ **Department of Spatial Information Engineering, Pukyong National University \\ ***NASA Goddard Space Flight Center
}

\begin{abstract}
Total Vertical Column Density (VCD) of $\mathrm{NO}_{2}$, a key component in air quality and tropospheric chemistry was measured using a ground-based instrument, Pandora, in Seoul from March 2012 to October 2013. The $\mathrm{NO}_{2}$ measurements using Pandora were compared with those obtained by satellite remote sensing from Ozone Monitoring Instrument (OMI) where the intercomparison characteristics were analyzed as a function of measurement geometry, cloud amount and aerosol loading. The negative biases of the $\mathrm{OMI} \mathrm{NO}_{2}$ VCD were larger when cloud amount and Aerosol Optical Depth (AOD) were higher. The correlation coefficient between $\mathrm{NO}_{2}$ VCDs from Pandora and OMI was 0.53 for the entire measurement period, whereas the correlation coefficient between the two was 0.74 when the cloud amount and AOD were low (cloud amount $<3$, $\mathrm{AOD}<0.4$ ). The low bias of OMI data was associated with the shielding effect of the cloud and the aerosols.
\end{abstract}

Key Words : $\mathrm{NO}_{2}$ VCD, Pandora, OMI, Validation, Seoul

\section{Introduction}

Nitrogen dioxide $\left(\mathrm{NO}_{2}\right)$ emissions from fossil fuel combustion and biomass burning affects global air quality and tropospheric chemistry (Seinfeld and Pandis, 2006). $\mathrm{NO}_{2}$ is formed by anthropogenic source such as high-temperature combustion of fossil fuel, and comes mainly from motor vehicle exhaust and stationary sources such as power plant. It is also produced naturally by soil, undersea microorganism, and lightning. $\mathrm{NO}_{2}$ plays an important role in atmosphere chemistry as it is a strong oxidizing agent that reacts in the air to form corrosive nitric acid, as well as toxic organic nitrates. $\mathrm{NO}_{2}$ also plays an important role in the photochemical smog to produce groundlevel ozone. High levels of $\mathrm{NO}_{2}$ affect the public health by respiratory and cardiovascular problems. In East Asia, top-down emission inventory, which is based on

Received December 17, 2013; Accepted December 23, 2013.

† Corresponding Author: Jhoon Kim (jkim2@yonsei.ac.kr)

This is an Open-Access article distributed under the terms of the Creative Commons Attribution Non-Commercial License (http://creativecommons. org/licenses/by-nc/3.0) which permits unrestricted non-commercial use, distribution, and reproduction in any medium, provided the original work is properly cited 
satellite measurements, suggested that $\mathrm{NO}_{2}$ emission from China increased substantially during the period of 1996-2004. Han et al. (2011) compared model-predicted $\mathrm{NO}_{2}$ column densities with OMI measurements to assess the current emission inventory over Korea (Han et al., 2011). Mijling et al. (2013) estimated $\mathrm{NO}_{2}$ emission trend over East Asia by using satellite measurement of Global Ozone Monitoring Experiment (GOME-2) (Mijling et al., 2013). However, satellite based measurements has relatively high uncertainties compared to the ground-based measurements due to its different sensitivity with respect to altitude, even though satellite measurements provide large spatial coverage (Boersma et al., 2007).

Thus, it is important to validate the satellite based measurements via comparison with ground-based measurements such as Pandora (Herman et al., 2009) and MAX-DOAS (Irie et al., 2008; Lee et al., 2011). The previous study (Herman et al., 2009) has shown that $\mathrm{NO}_{2}$ Vertical Column Density (VCDs) retrieved from satellite-based Ozone Monitoring Instrument (OMI) and ground-based Pandora were well correlated $(\mathrm{R}=0.73$, slope $=0.98)$ in Eastern U.S. However, the validation of $\mathrm{OMI} \mathrm{NO}_{2}$ total $\mathrm{VCD}$ products has not been performed in East Asia where the emissions are persistently high and the characteristics of atmospheric states are different from the Eastern USA. In this study, The $\mathrm{NO}_{2}$ VCD products of OMI are compared with those obtained from the ground-based Pandora measurement at Seoul, a site in East Asia. The spatiotemporal characteristics of $\mathrm{NO}_{2} \mathrm{VCD}$ measured by OMI and Pandora are also shown to analyze the difference.

\section{Measurements}

Pandora is located on the rooftop of Science Hall at Yonsei University in Seoul $\left(37.56^{\circ} \mathrm{N}, 126.94^{\circ} \mathrm{E}\right) 70 \mathrm{~m}$ above the sea level, as shown in Fig. 1(a). The location is more than $300 \mathrm{~m}$ far from the main traffic load, thus the effect of near local emission from the load can be negligible. Pandora is a passive system which measures direct sunlight from $270 \mathrm{~nm}$ to $530 \mathrm{~nm}$ with $0.5 \mathrm{~nm}$ spectral resolution. Its field of view is $1.6^{\circ}$, and the pointing precision is $0.01^{\circ}$. From the measured solar radiance, the trace gases total column densities are retrieved using the Differential Optical Absorption Spectroscopy (DOAS) technique (Herman et al., 2009). The $\mathrm{NO}_{2}$ fitting window of Pandora is between $370 \mathrm{~nm}$ and $500 \mathrm{~nm}$. The temporal resolution of Pandora measurement is about 2 minutes. The precision of Pandora $\mathrm{NO}_{2} \mathrm{VCD}$ is $0.01 \mathrm{DU}$ and that of accuracy is \pm 0.05 DU (Herman et al., 2009). The more information of Pandora was described in Herman et al. (2009). Pandora measurements have been carried out in Seoul from March 2012 to October 2013. The data with error less than $0.05 \mathrm{DU}\left(1 \mathrm{DU}=2.67 \times 10^{16} \mathrm{molecules} / \mathrm{cm}^{2}\right)$ are used for the inter-comparison.

OMI onboard Earth Observing System (EOS) Aura satellite was launched on July 15, 2004 following the mission of Total Ozone Mapping Spectrometer (TOMS). OMI measures the ultraviolet and visible radiance between $270 \mathrm{~nm}$ and $500 \mathrm{~nm}$ with the spectral resolution of $0.5 \mathrm{~nm}$. OMI has wide field of view of $114^{\circ}$, to have swath as wide as $2600 \mathrm{~km}$, so that it can measure the whole globe within a day (Levelt et al., 2006). The measurement principle of OMI is described in Fig. 1(b). Operational base-line product of $\mathrm{NO}_{2} \mathrm{OMI}$ algorithm employs direct fitting method (BOAS) (Levelt et al., 2006). The fitting window of $\mathrm{NO}_{2}$ is between $365 \mathrm{~nm}$ and $500 \mathrm{~nm}$ where average spectrum resolution is $0.63 \mathrm{~nm}$. The spatial resolution of $\mathrm{OMI}$ is $13 \times 24 \mathrm{~km}^{2}$ in normal mode and $13 \times 12 \mathrm{~km}^{2}$ in zoom mode (Levelt et al., 2006). The local overpass time of OMI over Seoul is at around 13:30.

In this study, the OMI level $2 \mathrm{G}$ products (OMNO2G) were used from National Aeronautics and Space Administration (NASA) website (http://disc.sci. gsfc.nasa.gov/Aura/data-holdings/OMI). For the 


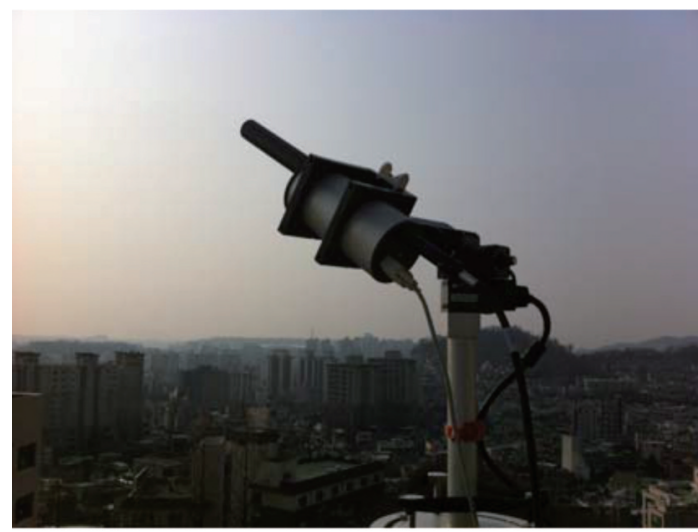

(a)

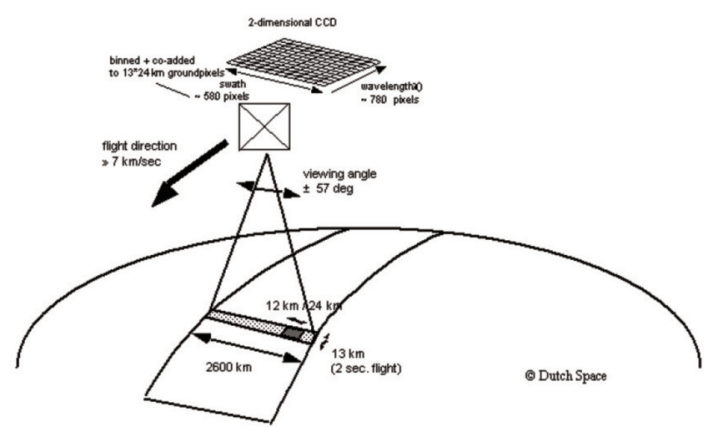

(b)

Fig. 1. (a) Pandora at Yonsei University, Seoul, Korea and (b) the OMI measurements (Levelt et al., 2006).

comparison, Pandora data were averaged in \pm 30 minutes overpass time of OMI. OMI data was spatially averaged within $20 \mathrm{~km}$ from Yonsei University considering the OMI spatial resolution. In order to avoid uncertainties caused by the cloud contaminations, the OMI data is used with cloud fraction less than 0.2.

\section{Results}

The retrieved $\mathrm{NO}_{2}$ VCDs from Pandora were compared with the OMI values as shown in Fig. 2. The correlation coefficient between $\mathrm{NO}_{2} \mathrm{VCD}$ from Pandora and OMI was 0.53 , with the number of coincident data of 166 . This overall comparison showed the correlation coefficient between the OMI and the Pandora in Seoul, Korea lower than the results of Herman et al. (2009), which were carried out in the U.S. and Greece. This implies a possibility for the effect of different environment between the East Asia and U.S./Europe, for example high aerosol loading and cloud characteristics. The slope obtained from the regression equation in Fig.2 is 0.33, showing the OMI $\mathrm{NO}_{2}$ VCD values are underestimated compared to the Pandora data.

Fig. 3 shows the difference between $\mathrm{NO}_{2} \mathrm{VCD}$ from Pandora and OMI measurements at various cloud

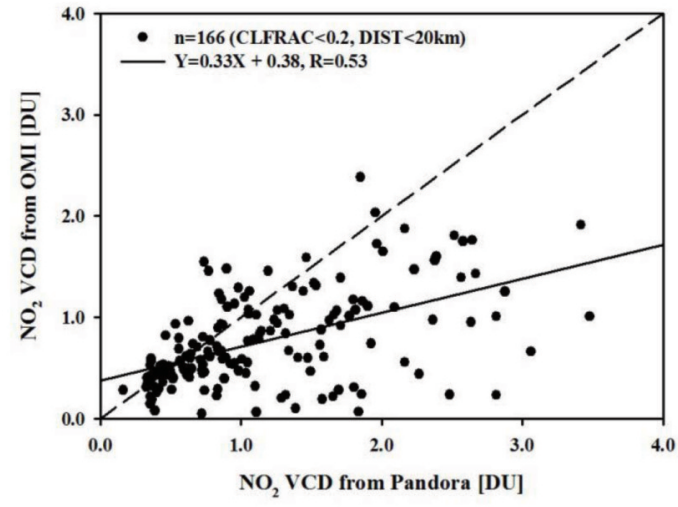

Fig. 2. Correlation between $\mathrm{NO}_{2} \mathrm{VCDs}$ from OMl and Pandora measurements.

amounts at nearest overpass time of OMI in Seoul. The cloud amount data was obtained from Korean Meteorological Administration (KMA) station in Seoul, which is located $2.5 \mathrm{~km}$ to east of Yonsei University. The difference between $\mathrm{NO}_{2} \mathrm{VCD}$ from Pandora and OMI was larger when cloud amount was higher. These differences can be attributed to shielding effect of cloud on the column density retrieval of OMI. As shown in the figure, the cloud amount between the OMI (closed square) and ground observation of KMA (abscissa) shows good correlation but large difference due to the different observation geometry such as viewing zenith angle, and corresponding spatial resolution.

Similar tendency is also shown in the relationship between the differences and Aerosol Optical Depth 

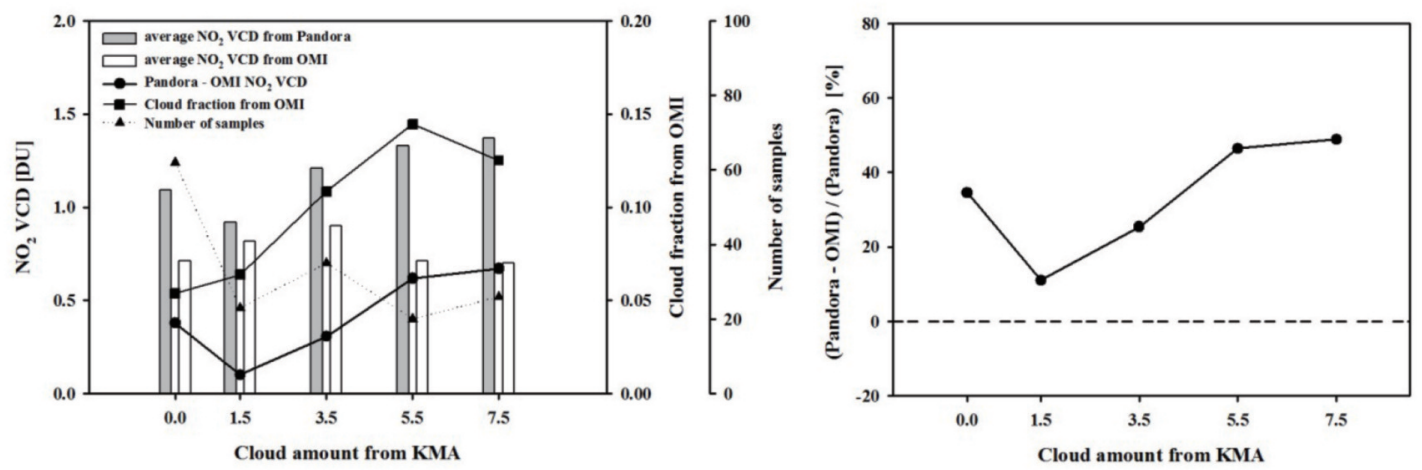

Fig. 3. Difference between $\mathrm{NO}_{2}$ VCDs from Pandora and OMI measurements for different cloud amounts.
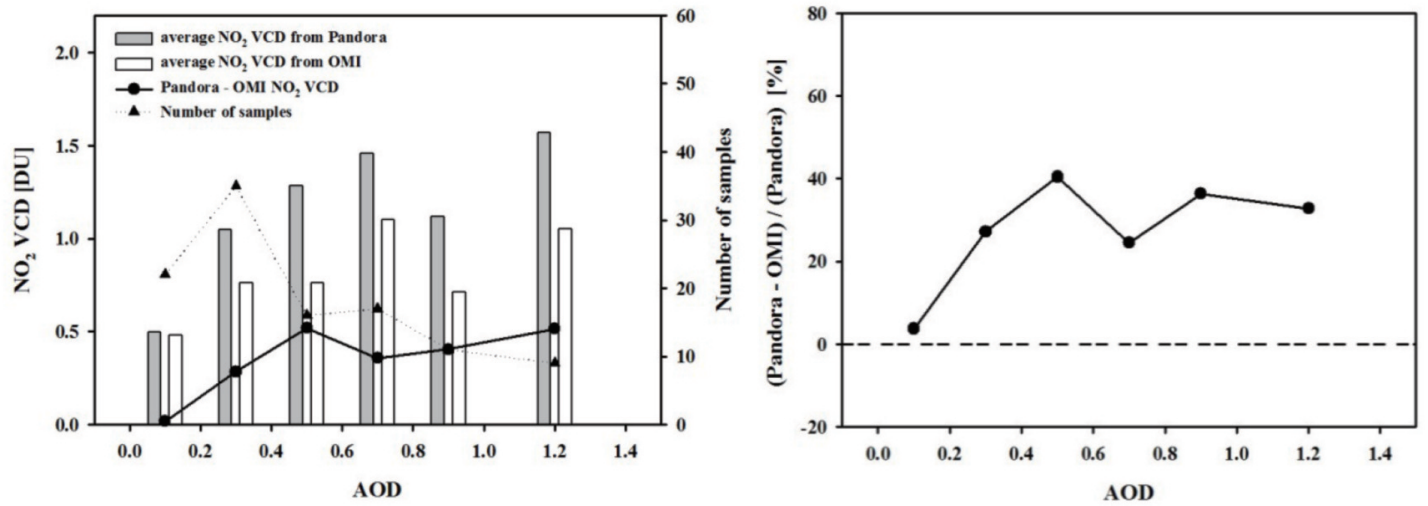

Fig. 4. Difference between $\mathrm{NO}_{2}$ VCDs from Pandora and OMI measurements at various $\mathrm{AOD}$.
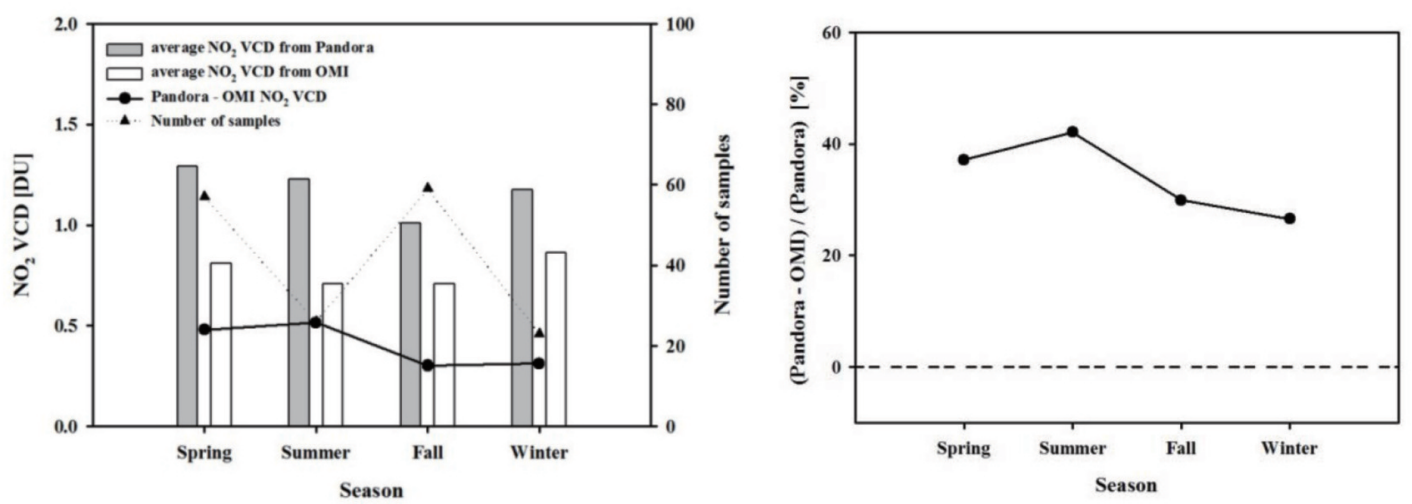

Fig. 5. Seasonal differences between $\mathrm{NO}_{2}$ VCDs obtained from Pandora and OMI.

(AOD). Fig. 4 shows the difference between $\mathrm{NO}_{2} \mathrm{VCD}$ from Pandora and OMI measurements as a function of $\mathrm{AOD}$ at $440 \mathrm{~nm}$ at the same site of Yonsei University, one of the AErosol RObotic NETwork (AERONET) site (http://aeronet.gsfc.nasa.gov/). For the comparison, AERONET data at Yonsei University were averaged for \pm 30 minutes of the OMI overpass time. The difference between $\mathrm{NO}_{2}$ VCD from Pandora and OMI was nearly zero when AOD interval is between 0 and 0.2 . As AOD becomes larger, the biases became higher which also might be associated with the shielding effect of the aerosols. 

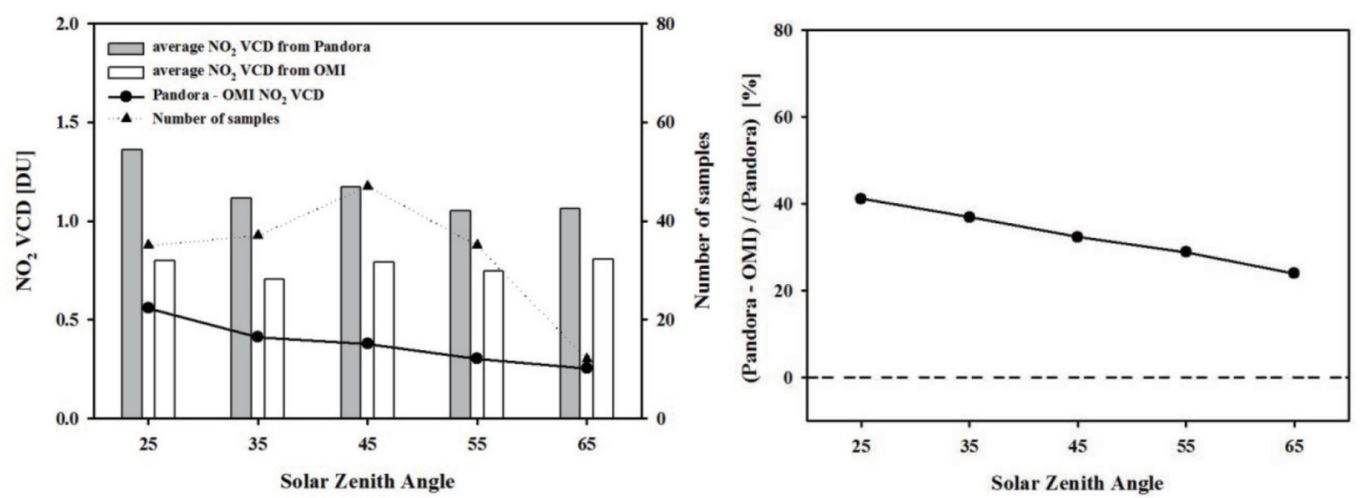

Fig. 6. Difference between $\mathrm{NO}_{2}$ VCD from Pandora and OMI measurements at various solar zenith angles.

Fig. 5 shows the difference of $\mathrm{NO}_{2}$ VCDs between the Pandora and the OMI in each season. The mean $\mathrm{NO}_{2}$ VCDs from Pandora were 1.30, 1.23, 1.01, and 1.18 DU in spring, summer, fall, and winter, respectively, whereas those from OMI were $0.81,0.71$, 0.71 , and $0.86 \mathrm{DU}$, respectively. $\mathrm{NO}_{2} \mathrm{VCD}$ of $\mathrm{OMI}$ was systematically smaller than those of Pandora by $0.49,0.52,0.30$, and 0.32 DU in spring, summer, fall, and winter, respectively. The difference of $\mathrm{NO}_{2}$ total VCDs from Pandora and OMI were larger in spring and summer than those in fall and winter.

Fig. 6 shows the difference between Pandora and OMI $\mathrm{NO}_{2}$ VCD measurements as a function of solar zenith angle (SZA). SZAs from Pandora and OMI products were very close, thus averaged for the coincide measurements. The difference between $\mathrm{NO}_{2}$ VCDs from Pandora and OMI was larger when SZA was low. Table 1 shows the correlation between retrieved $\mathrm{NO}_{2}$ VCDs from Pandora and OMI at different SZAs. The correlation coefficient between $\mathrm{NO}_{2}$ VCD from Pandora and OMI was the highest ( $\mathrm{R}$ $=0.82$ ) when SZA interval is between $30^{\circ}$ and $40^{\circ}$, while it was the lowest when SZA is larger than $60^{\circ}$ as shown in Fig. 7. Since Pandora uses Geometric Air Mass Factor (GAMF) for conversion of Slant Column Density (SCD) into VCD, it is likely to have small errors in the Pandora data. Thus, the biases can be attributed to the uncertainties in the AMF calculations
Table 1. Relationship between $\mathrm{NO}_{2}$ VCDs obtained from Pandora and OMI measurements at different solar zenith angles

\begin{tabular}{c|c|c|c|c}
\hline \hline & Slope & Intercept & $\mathrm{R}$ & Number of data \\
\hline $\mathrm{SZA}<30^{\circ}$ & 0.28 & 0.42 & 0.50 & 35 \\
\hline $30^{\circ}<\mathrm{SZA}<40^{\circ}$ & 0.45 & 0.21 & 0.82 & 37 \\
\hline $40^{\circ}<\mathrm{SZA}<50^{\circ}$ & 0.35 & 0.38 & 0.51 & 47 \\
\hline $50^{\circ}<\mathrm{SZA}<60^{\circ}$ & 0.31 & 0.42 & 0.40 & 35 \\
\hline $60^{\circ}<\mathrm{SZA}$ & 0.17 & 0.62 & 0.28 & 12 \\
\hline \hline
\end{tabular}

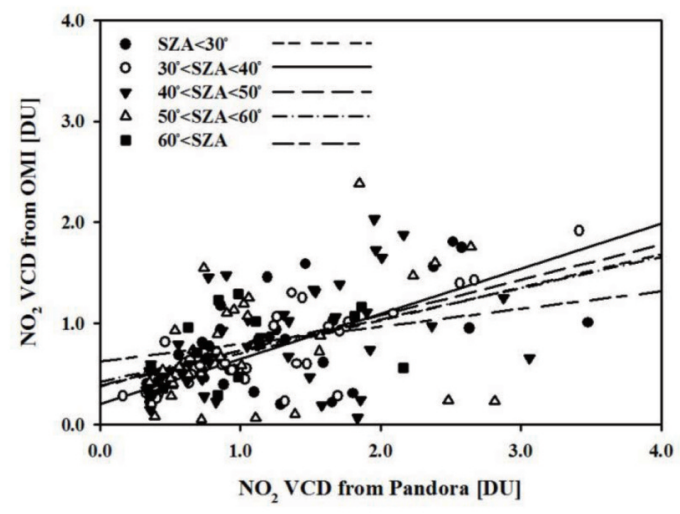

Fig. 7. Relationship between $\mathrm{NO}_{2}$ VCDs obtained from Pandora and $\mathrm{OMI}$ measurements at various solar zenith angles.

for the OMI data. The differences in the two methods, aerosol loading, cloud characteristics and the spatial variability of $\mathrm{NO}_{2}$ in Seoul with complicated $\mathrm{NO}_{\mathrm{X}}$ emission locations are thought to cause larger difference in $\mathrm{NO}_{2} \mathrm{VCD}$ obtained from the two methods than those found at the previous investigation (Herman et al., 2009).

Fig. 8 shows the variations of difference in $\mathrm{NO}_{2}$ 

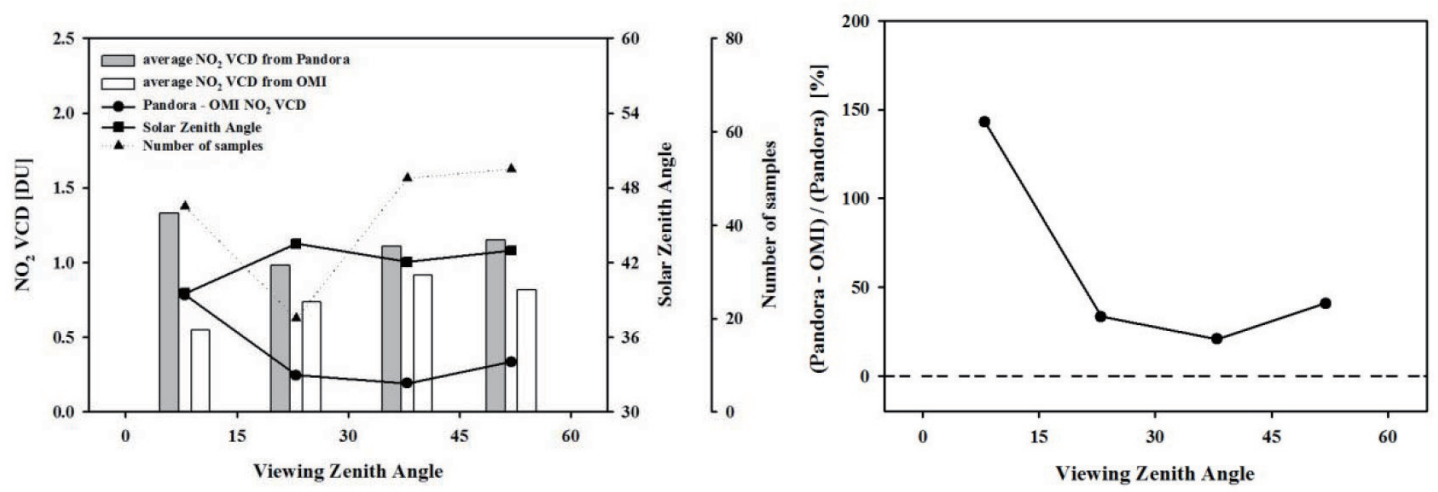

Fig. 8. Difference between $\mathrm{NO}_{2}$ VCDs obtained from Pandora and OMI measurements at various viewing zenith angles.
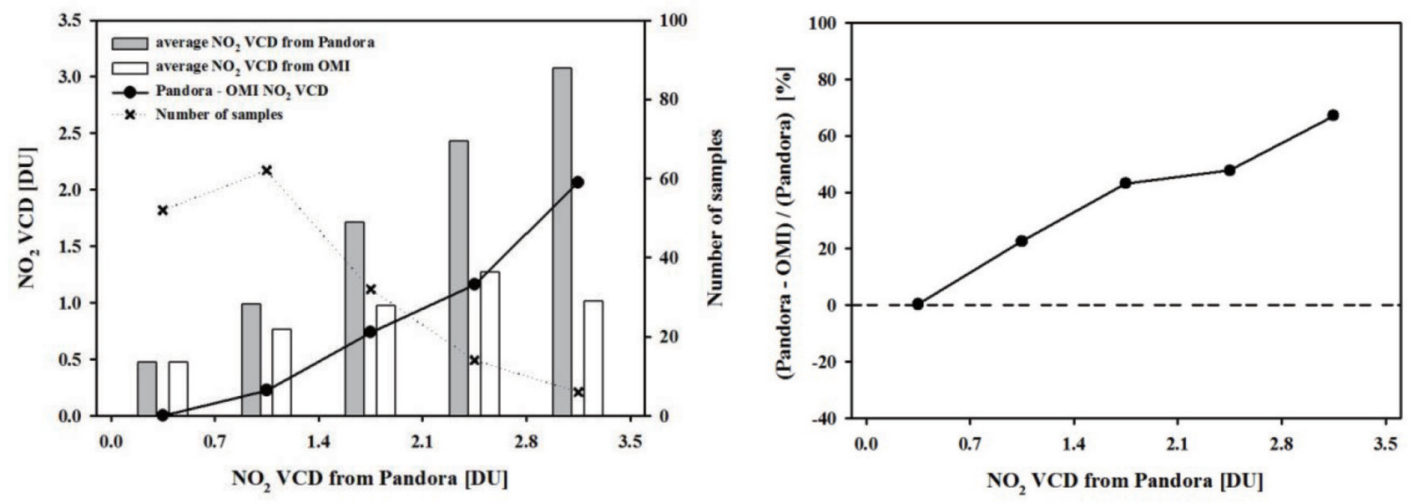

Fig. 9. Difference of $\mathrm{NO}_{2}$ VCD between Pandora and OMI as a function of Pandora VCD.

VCDs obtained from Pandora and OMI depending on various Viewing Zenith Angles (VZA) of OMI. The difference between $\mathrm{NO}_{2}$ VCDs from Pandora and OMI was larger when VZA was low, although the opposite trends are expected in general. This may be explained with the different geometry between the Pandora and OMI for the intercomparison. As the OMI is in sunsynchronous orbit, the SZA for the OMI measurements at Seoul changes by season only thus remains within $40^{\circ}$ and $43^{\circ}$, while the viewing zenith angle may change widely depending on the viewing geometry of the satellite.

Fig. 9 shows the variations of difference in $\mathrm{NO}_{2}$ VCDs obtained from Pandora and OMI depending on the Pandora $\mathrm{NO}_{2} \mathrm{VCD}$. The difference between the two $\mathrm{NO}_{2}$ VCDs tends to be larger both in the absolute values and relative (\%) when the $\mathrm{NO}_{2} \mathrm{VCD}$ of Pandora measurements are large. This tendency can be explained with the high concentrations of $\mathrm{NO}_{2}$ usually indicate heavily polluted condition, thus the aerosol loading is expected to be high, as shown in Fig. 4. Thus, it is likely that the large aerosol contamination increase the uncertainty in $\mathrm{NO}_{2}$ measurements.

In order to avoid the contamination by aerosol and clouds for the $\mathrm{NO}_{2}$ measurements, the retrieved $\mathrm{NO}_{2}$ VCDs from Pandora and OMI are compared when the cloud amount is less than 3 and AOD is less than 0.4, as shown in Fig. 10. The correlation coefficient between $\mathrm{NO}_{2}$ VCD from Pandora and OMI was increased to 0.74 with the number of coincident data of 40. The slope and y-intercept between Pandora and OMI measurements were 0.49 and 0.25 , respectively. The regression line slope of 0.49 shows that the OMI $\mathrm{NO}_{2}$ VCD values are still underestimated compared to 


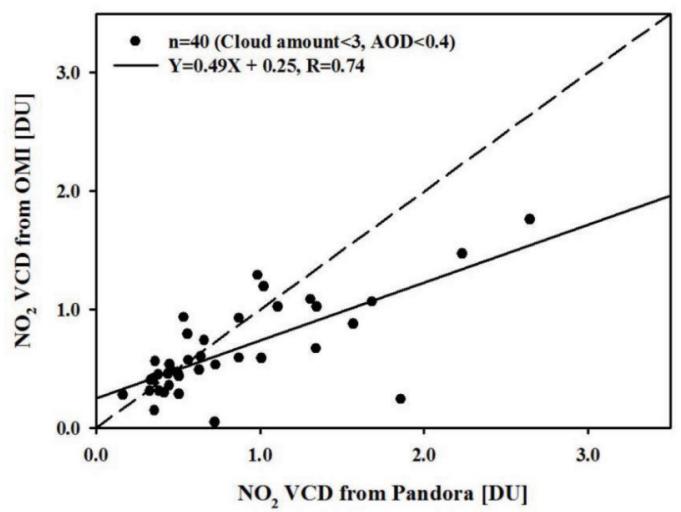

Fig. 10. Correlation between $\mathrm{NO}_{2}$ VCDs from OMl and Pandora measurements for conditions where the cloud amount and $A O D$ were low.

the Pandora data. However, the correlation coefficient $(\mathrm{R}=0.74)$ between OMI and Pandora measurement was higher when the cloud amount and AOD were low, than the value ( $\mathrm{R}=0.53$ ) between the two $\mathrm{NO}_{2}$ VCDs for the entire measurement period. Thus, it can be inferred that the morphology and condition for clouds and aerosols increase the uncertainty of the retrieved OMI $\mathrm{NO}_{2} \mathrm{VCD}$, since the shielding effect of the cloud and the aerosols may result in high uncertainty for the contaminated radiance fraction thus the air mass factor.

\section{Summary and Conclusion}

$\mathrm{NO}_{2} \mathrm{VCD}$ was measured using the ground-based Pandora from March 2012 to October 2013 in Seoul, Korea, and was compared with the coincident $\mathrm{NO}_{2}$ VCD obtained from OMI. The correlation coefficient between the $\mathrm{NO}_{2}$ VCDs from Pandora and OMI was 0.53. It was found that the correlation coefficient between the $\mathrm{NO}_{2}$ VCD from OMI and Pandora was lower than the results of Herman et al. (2009) for the U.S. and Greece. The $\mathrm{NO}_{2} \mathrm{VCD}$ of $\mathrm{OMI}$ is underestimated compared to the Pandora measurements with the regression line slope of 0.33 . For conditions where the cloud amount and AOD were low, the correlation coefficient between the $\mathrm{NO}_{2} \mathrm{VCDs}$ from
Pandora and OMI was increased to 0.74 , with the slope and $y$-intercept of 0.49 and 0.25 , respectively. The underestimation of OMI data was associated with cloud amount and AOD, which can be attributed to the different geometry and thus the uncertainties in the AMF calculations for the OMI data. However, the $\mathrm{NO}_{2}$ VCD difference between the two measurements decreased as SZA increased. Thus, the differences in the geometry and spatial coverage of the two methods cause the difference in $\mathrm{NO}_{2} \mathrm{VCD}$ obtained from the two measurements. In general, the tropospheric $\mathrm{NO}_{2}$ often causes the enhancement in $\mathrm{NO}_{2} \mathrm{VCD}$ due to the less variability of stratospheric $\mathrm{NO}_{2}$, the further investigations need to be taken with measurements of the same spatial coverage and tropospheric $\mathrm{NO}_{2}$ to identify the sources for such underestimation in $\mathrm{NO}_{2}$ VCD in Seoul measured by OMI.

\section{Acknowledgment}

This work was funded by the Korea Meteorological Administration Research and Development Program under Grant CATER 2012-2065, and it was also supported by the Brain Korea 21 plus program.

\section{Reference}

Boersma, K.F., H.J. Eskes, J.P. Veefkind, E.J. Brinksma, R.J. van der A, M. Sneep, G.H.J. van den Oord, P.F. Levelt, P. Stammes, J.F. Gleason, and E.J. Bucsela, 2007. Near-real time retrieval of tropospheric $\mathrm{NO}_{2}$ from OMI, Atmos Chem Phys 7: 2103-2118.

Han, K.M., C.K. Lee, J. Lee, J. Kim, and C.H. Song, 2011. A comparison study between modelpredicted and OMI-retrieved tropospheric $\mathrm{NO}_{2}$ columns over the Korean peninsula, Atmos Environ, 45: 2962-2971. 
Herman, J., A. Cede, E. Spinei, G. Mount, M. Tzortziou, and N. Abuhassan, 2009. $\mathrm{NO}_{2}$ column amounts from ground-based Pandora and MFDOAS spectrometers using the directsun DOAS technique: Intercomparisons and application to OMI validation, J Geophys ResAtmos, 114.

Irie, H., Y. Kanaya, H. Akimoto, H. Tanimoto, Z. Wang, J.F. Gleason, and E.J. Bucsela, 2008. Validation of OMI tropospheric $\mathrm{NO}_{2}$ column data using MAX-DOAS measurements deep inside the North China Plain in June 2006: Mount Tai Experiment 2006, Atmos Chem Phys, 8: 6577 6586.

Lee, H., J. Ryu, J. Kim, Y. Noh, and Y. Yoon, 2011. Combined measurements of a UV mini MAXDOAS system and a TX for retrieval of ambient trace gas mixing ratio: Comparisons with combined RTM and MAX-DOAS methods. Atmos Environ, 45: 7218-7226.

Levelt, P.F., G.H.J Van den Oord, M.R. Dobber, A. Malkki, H. Visser, J. de Vries, P. Stammes, J.O.V. Lundell, H. Saari, 2006. The Ozone Monitoring Instrument, Ieee T Geosci Remote, 44: 1093-1101.

Mijling, B., R.J. van der A, Q. Zhang, 2013. Regional nitrogen oxides emission trends in East Asia observed from space. Atmos Chem Phys, 13: 12003-12012.

Richter, A., J.P. Burrows, H. Nuss, C. Granier, U. Niemeier, 2005. Increase in tropospheric nitrogen dioxide over China observed from space, Nature, 437: 129-132.

Seinfeld, J.H., S.N. Pandis, 2006. Atmospheric chemistry and physics from air pollution to climate change, Wiley/interscience, New York. 